\title{
Chlamydophila pneumoniae, Mycoplasma pneumoniae, and influenza in children with respiratory infections in Alexandria, Egypt
}

\author{
Tiziana Grassi ${ }^{1}$, Fabiola Mancini ${ }^{1}$, Alessandra Ciervo ${ }^{1}$, Maria Fenicia Vescio ${ }^{1}$, Abeer Ghazal ${ }^{2}$, Housam \\ Ashour $^{3}$, Ezzeldin Saleh ${ }^{2}$, Mahmoud El Zalabani ${ }^{3}$, Isabella Donatelli ${ }^{1}$, Gamal El Sawaf ${ }^{2}$, Giovanni Rezza ${ }^{1}$ \\ ${ }^{1}$ Department of Infectious, Parasitic and Immune-Mediated Diseases, National Public Health Institute, Rome, Italy \\ ${ }^{2}$ Medical Research Institute, Alexandria University, Alexandria, Egypt \\ ${ }^{3}$ Faculty of Medicine, Alexandria University, Alexandria, Egypt
}

\begin{abstract}
Introduction: Acute respiratory infections (ARI) are the leading cause of pediatric morbidity and mortality worldwide. Information about etiological agents of ARI in developing countries is still limited.

Methodology: Throat swabs collected from children hospitalized with ARI between December 2009 and May 2010 were investigated for Chlamydophila pneumoniae, Mycoplasma pneumoniae, and influenza viruses by molecular analyses.

Results: This study conducted in Alexandria, Egypt, was designed to determine the prevalence of several microorganisms in 156 children hospitalized with ARI. Overall, samples from 76 individuals (49\%) were found to be positive for at least one pathogen, and 10 of them were positive for two agents. C. pneumoniae was the most commonly detected agent, followed by M. pneumonia and H1N1 pandemic influenza virus. Positivity for $C$. pneumoniae was associated with colder months and mild disease of the upper respiratory tract such as laryngitis. Conclusions: Further studies are needed to identify other possible agents of ARI (e.g., RSV, adenoviruses, other bacterial infections) in this population and to better understand the causal role of atypical bacteria detected in respiratory samples.
\end{abstract}

Key words: Chlamydophila pneumoniae; Mycoplasma pneumoniae; influenza viruses; acute respiratory infections; real-time PCR; Egypt

J Infect Dev Ctries 2014; 8(3):379-383. doi:10.3855/jidc.4458

(Received 26 November 2013 - Accepted 11 January 2014)

Copyright (C) 2014 Grassi et al. This is an open-access article distributed under the Creative Commons Attribution License, which permits unrestricted use, distribution, and reproduction in any medium, provided the original work is properly cited.

\section{Introduction}

Acute respiratory infections (ARIs) are classified as upper respiratory tract infections (URTIs) or lower respiratory tract infections (LRTIs) [1]. Several bacteria and viruses are implicated in ARI, and coinfections may also occur. The evaluation of coinfections and of the relative importance of each potential pathogen may contribute to improved understanding of the etiopathogenesis of ARI; however, identifying the etiological agent is challenging, due to frequent unavailability of adequate clinical samples and difficult differentiation between infection and colonization [2,3]. In particular, the roles of Chlamydophila pneumoniae and Mycoplasma pneumoniae, which are considered causal agents of the so-called atypical pneumonia, in the etiology of ARI are not completely defined, since these organisms are difficult to cultivate from respiratory tract specimens $[2,4]$. Furthermore, variability exists among studies in the reliability and interpretation of the results of serological assays. Molecular diagnostic techniques, such as polymerase chain reaction (PCR), which have become useful tools for the etiological diagnosis of LRTIs, may contribute to the identification of these agents and possible co-infections with respiratory viruses.

Little information is available about the etiology of ARI in developing countries, even though it is known that bacterial pathogens appear to play the major role in severe cases of disease $[5,6]$. Studies conducted in African countries found a high frequency of infections due to atypical bacteria such as $C$. pneumoniae and $M$. pneumoniae; however, different laboratory methods were used to detect different pathogens [7,8]. We previously investigated the frequency of atypical bacteria and respiratory viruses among children affected by ARI in Alexandria, Egypt; however, the short study period was limited to the end of the flu season [9]. Thus, we planned a study with the aim of investigating the role of atypical bacteria such as $C$. pneumoniae and $M$. pneumoniae during the entire influenza season. Here, we report the results of this study. 


\section{Methodology}

Patients and samples

The study site was the largest pediatric hospital in Alexandria, Egypt. All children presenting to the emergency unit with symptoms suggestive of ARI between the end of December 2009 and May 2010 were eligible for the study. The age range of the patients was between 0 and 18 years. ARI was defined by the presence of fever $\geq 38^{\circ} \mathrm{C}$, at least one respiratory symptom (cough, sore throat, nasal congestion, or rhinitis), and at least one constitutional symptom (headache, malaise, myalgia, thrill or sweats, retrosternal pain, asthenia). Throat swabs were collected from each participant using Virocult swabs (Medical Wire and Equipment, Corsham, UK). Information about date of sample collection, gender, age, residence, clinical symptoms, presumed clinical diagnosis, and current therapy was also collected.

The study was approved and carried out under the guidelines of the Ethical Committee of the Medical Research Institute, Alexandria University, Alexandria, Egypt. Informed consent was obtained from the parents/guardians of all participating children.

\section{Laboratory methods}

Throat swabs were divided in separate aliquots $(100 \mu \mathrm{L})$ and stored at $-80^{\circ} \mathrm{C}$ for molecular analyses, which were performed at Istituto Superiore di Sanità, Rome, Italy.

Nucleic acids were extracted from separate aliquots of the clinical samples. The viral RNA was obtained by the QIAamp Viral RNA Mini Kit (Qiagen, Hilden, Germany), in accordance with the manufacturer's instructions. Human influenza type A and type B viruses were identified using previously described methods [10]. For bacterial identification, total DNA was extracted by using the commercial kit Wizard SV Genomic DNA Purification System (Promega, Madison, USA), following the manufacturer's instructions. DNA samples were subjected to real-time PCR for C. pneumoniae or PCR for $M$. pneumoniae, as previously described $[11,12]$.

\section{Statistical analysis}

Univariate and multivariate logistic regression models were used to identify factors and clinical signs or symptoms associated with $C$. pneumoniae infection; ORs (and their 95\% confidence intervals) were calculated to estimate the strength of the associations. All the analyses were carried out using STATA 10 (StataCorp, College Station, TX, USA).
Figure 1. Monthly distribution of the cases by etiological agent

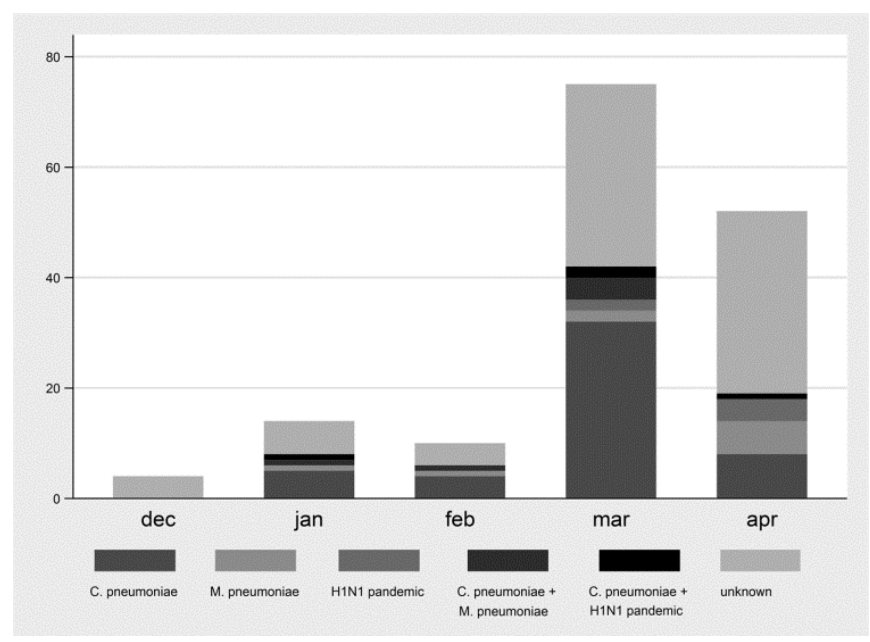

\section{Results}

During the study period, 156 children were recruited: 104 (66.7\%) in December-February, and 52 (33.3\%) in April. There was no cases seen in the months of March and May. Of all the patients, 110 $(70.5 \%)$ were from the urban area of Alexandria, and $46(29.5 \%)$ from neighboring rural areas. The median age of the participants was 1 year (range: $0-18$ years), and $88(56.0 \%)$ of them were males.

With regard to clinical presentation, URTI and LRTI were detected in 47 (30.1\%) and $103(66.0 \%)$ of the study participants, respectively. The most represented agent was $C$. pneumoniae $(68.6 \%)$, while M. pneumoniae (19.8\%) and influenza viruses (11.6\%) were less represented (Table 1). C. pneumoniae and M. pneumoniae co-infection was observed in $3.8 \%$ of the cases. In addition, co-infection between $C$. pneumoniae and influenza virus was detected in $2.6 \%$ of the cases. The monthly distribution of the cases by etiological agent is presented in Figure 1.

Results from the univariate analysis are reported in Table 2. The analysis showed that the risk of $C$. pneumoniae detection was about 3.94 (1.66-9.33) times higher in February and March than in April. Moreover, children affected by $C$. pneumoniae were more likely to report laryngitis (OR 13.61, 95\% CI: $1.59 ; 116.68)$. After controlling for age, sex, living in a rural area, and clinical syndromes, $C$. pneumoniae remained significantly associated with month of diagnosis (OR: 3.21: 1.25; 8.22). 
Table 1. Number of positive samples and number and type of strains identified among the participants at the study

\begin{tabular}{lcc}
\hline Pathogens & Samples & Agents \\
\cline { 2 - 3 } C. pneumoniae & $\mathrm{n}(\%)$ & $\mathrm{n}(\%)$ \\
M. pneumoniae & $49(31.4)$ & $59(68.6)$ \\
H1N1 pandemic influenza virus & $11(7.1)$ & $17(19.7)$ \\
C. pneumoniae + M. pneumoniae & $6(3.8)$ & $10(11.6)$ \\
C. pneumoniae + H1N1 pandemic & $6(3.8)$ & $4(2.6)$ \\
Unknown & $78(50.0)$ & $86(100)$ \\
Total & $156(100)$ & \\
\hline
\end{tabular}

Table 2. Epidemiological and clinical correlates of C. pneumoniae infection ${ }^{\S}$

\begin{tabular}{|c|c|c|c|c|c|c|}
\hline \multirow{2}{*}{ Parameters } & \multicolumn{2}{|c|}{ C. pneumoniae } & \multicolumn{2}{|c|}{ Other } & \multirow{2}{*}{$\begin{array}{l}\text { Odds } \\
\text { ratios }\end{array}$} & \multirow{2}{*}{$\begin{array}{l}95 \% \text { confidence } \\
\text { interval }\end{array}$} \\
\hline & $n=49$ & $\%$ & $\mathbf{n}=97$ & $\%$ & & \\
\hline Months of age ${ }^{*}$ & \multicolumn{2}{|c|}{$19.94 \pm 21.02$} & \multicolumn{2}{|c|}{$23.81 \pm 35.22$} & 1.00 & $(0.98 ; 1.00)$ \\
\hline \multicolumn{7}{|l|}{ Sex } \\
\hline Male & 30 & $(63.8)$ & 52 & $(59.1)$ & 1 & \\
\hline Female & 17 & $(36.2)$ & 36 & $(40.9)$ & 1.37 & $(0.64 ; 2.91)$ \\
\hline \multicolumn{7}{|l|}{ Type of area of residence } \\
\hline Rural area & 11 & $(22.4)$ & 35 & $(36.1)$ & 1 & \\
\hline Urban area & 38 & $(77.5)$ & 62 & $(63.9)$ & 2.10 & $(0.93 ; 4.74)$ \\
\hline \multicolumn{7}{|l|}{ Month of occurrence } \\
\hline April & 8 & $(16.3)$ & 43 & $(44.3)$ & 1 & \\
\hline December-March & 41 & $(83.7)$ & 54 & $(55.7)$ & 3.94 & $(1.66 ; 9.33)$ \\
\hline \multicolumn{7}{|l|}{ Type of infection } \\
\hline $\begin{array}{l}\text { Lower respiratory tract } \\
\text { infection }\end{array}$ & 28 & $(59.6)$ & 70 & $(74.5)$ & 1 & \\
\hline $\begin{array}{l}\text { Upper respiratory tract } \\
\text { infection }\end{array}$ & 19 & $(40.4)$ & 24 & $(25.5)$ & 2.26 & $(0.91 ; 5.62)$ \\
\hline \multicolumn{7}{|l|}{ Clinical syndromes } \\
\hline Laryngitis & 6 & $(12.2)$ & 1 & $(1.0)$ & 13.61 & $(1.58 ; 116.68)$ \\
\hline Bronchitis & 3 & $(6.1)$ & 17 & $(17.5)$ & 0.31 & $(0.08 ; 1.11)$ \\
\hline Pneumonia/pleuritis & 21 & $(42.6)$ & 41 & $(42.3)$ & 1.04 & $(0.51 ; 2.11)$ \\
\hline Bronchiolitis & 4 & $(8.2)$ & 12 & (12.4) & 0.63 & $(0.19 ; 2.09)$ \\
\hline \multicolumn{7}{|l|}{ Symptoms } \\
\hline Dry cough & 31 & $(63.3)$ & 55 & $(56.7)$ & 1.25 & $(0.61 ; 2.58)$ \\
\hline Productive cough & 7 & $(14.3)$ & 24 & $(24.7)$ & 0.54 & $(0.21 ; 1.37)$ \\
\hline Dyspnoea & 14 & $(28.6)$ & 20 & $(20.6)$ & 1.35 & $(0.59 ; 3.09)$ \\
\hline Sore throat & 21 & $(42.9)$ & 44 & $(45.4)$ & 0.96 & $(0.47 ; 1.94)$ \\
\hline
\end{tabular}

\footnotetext{
${ }^{\S \S}$ Ten individuals were excluded from the analysis because of co-infection with other agents

${ }^{* *}$ For the variable age, the mean and standard deviation are reported. Odds ratios for a month change in age.
} 


\section{Discussion}

There is limited knowledge about the microbial agents that play a major role in ARI in North Africa and the Middle East. To fill this gap, we conducted a study during the influenza season among children hospitalized in Alexandria, Egypt. C. pneumoniae was the most commonly detected microorganism in our study population; this finding is consistent with those of a previous study conducted in the same area over a shorter period of time [9]. C. pneumoniae was more likely to be detected in the colder months (from December to March) than in April and was significantly associated with URTIs such as laryngitis. M. pneumoniae was detected in $11 \%$ of the samples; in about one-third of the cases, it was associated with $C$. pneumoniae.

The H1N1 pandemic virus (A/California/2009) was found in only $6 \%$ of the samples, consistent with the previous study conducted in Alexandria, where influenza viruses were detected in $5 \%$ of the samples. Surprisingly, the highest rate of influenza virus was observed in April, in contrast to the usual trend reported in Europe. In four samples, H1N1 was found in the sample with $C$. pneumoniae, confirming the occurrence of co-infection between bacteria and viruses. There is little information from other studies conducted in the same area. However, previous studies conducted in Jordan found a high detection rate of RSV and adenovirus but very low rates of influenza virus [13].

Before drawing conclusions, possible limits and biases of the study should be mentioned. First of all, the identification of the cause of ARI remains challenging, due either to inadequate samples that may lead to false negative results, or to difficult interpretation of positive findings between infection and colonization. Secondly, the low proportion of cases attributable to influenza viruses might be explained by the place of recruitment, since influenza is usually underrepresented in hospital-based studies [14]. In a previous study conducted in the same site, the respiratory syncytial virus was detected in $7 \%$ of the samples, representing $8 \%$ of all isolates, compared with $5 \%$ for influenza [9]. Community-based studies would probably show contrasting results.

In conclusion, $C$. pneumoniae was the most frequently detected agent of ARI among children recruited in the pediatric hospital of Alexandria; this microorganism was associated with URTI, particularly laryngitis. Low rates of detection of influenza viruses were found. A high proportion of samples tested negative for the three agents under investigation.
Further studies are needed to identify other possible agents of ARI (e.g., RSV, adenoviruses, other bacterial infections) in this population and to better understand the causal role of atypical bacteria detected in respiratory samples.

\section{Acknowledgements}

This work was supported by a research grant from the Italian Ministry of Health (CCM).

\section{References}

1. Wardlaw T, Salama P, Johansson EW, Mason E (2006) Pneumonia: the leading killer of children. Lancet 368: 10481050 .

2. British Thoracic Society Guidelines for the Management of Community Acquired Pneumonia in Childhood (2002) British Thoracic Society Standards of Care Committee. Thorax Suppl 57: 1-24.

3. Tsolia MN, Psarras S, Bossios A, Audi H, Paldanius M, Gourgiotis D, Kallergi K, Kafetzis DA, Constantopoulos A, Papadopoulos NG (2004) Etiology of community acquired pneumonia in hospitalized school-age children: evidence for high prevalence of viral infections. Clin Infect Dis 39: 681686.

4. Niederman MS, Mandell LA, Anzueto A, Bass JB, Broughton WA, Campbell GD, Dean N, File T, Fine MJ, Gross PA, Martinez F, Marrie TJ, Plouffe JF, Ramirez J, Sarosi GA, Torres A, Wilson R, Yu VL (2001) American Thoracic Society. Guidelines for the management of adults with community-acquired pneumonia. Diagnosis, assessment of severity, antimicrobial therapy, and prevention. Am J Respir Crit Care Med 163: 1730-1754.

5. Mulholland K (2007) Childhood pneumonia mortality-a permanent global emergency. Lancet 370: 285-289.

6. Rudan I, Boschi-Pinto C, Biloglav Z, Mulholland K, Campbell H (2008) Epidemiology and aetiology of childhood pneumonia. Bull World Health Organ 86: 408-416.

7. Weber MW, Gopalakrishna G, Awomoyi A, Cunningham A, Adegbola RA, Falade AG, Ogunlesi OO, Whittle HC, Mulholland EK (2006) The role of Chlamydia pneumoniae in acute respiratory tract infections in young children in The Gambia, West Africa. Ann Trop Paediatr 26: 87-94.

8. Nokes DJ, Okiro EA, Ngama M, Ochola R, White LJ, Scott PD English M, Cane PA, Medley GF (2008) Respiratory syncytial virus infection and disease in infants and young children observed from birth in Kilifi District, Kenya. Clin Infect Dis 46: 50-57.

9. Ciervo A, Mancini F, Puzelli S, Interisano M, Vescio MF, Farchi F, Ghazal A, Ashour H, Saleh E, Andreoni M, El Zalabani M, Donatelli I, Rezza G, El Sawaf G (2010) Detection and correlates of Chlamydophila pneumoniae among children with acute respiratory infections. J Pediatric Infect Dis 5: 249-254.

10. Templeton KE, Scheltinga SA, Beersma MF, Kroes AC, Claas EC (2004) Rapid and sensitive method using multiplex real-time PCR for diagnosis of infections by influenza a and influenza $B$ viruses, respiratory syncytial virus, and parainfluenza viruses 1, 2, 3, and 4. J Clin Microbiol 42: 1564-1569. 
11. Ciervo A, Petrucca A Cassone A (2003) Identification and quantification of Chlamydia pneumoniae in human atherosclerotic plaques by LightCycler real-time-PCR. Mol Cell Probes 17: 107-111.

12. Cultrera R, Seraceni S, Germani R, Contini C (2006) Molecular evidence of Ureaplasma urealyticum and Ureaplasma parvum colonization in preterm infants during respiratory distress syndrome. BMC Infect Dis 6: 166.

13. Kaplan NM, Dove W, Abd-Eldayem SA, Abu-Zeid AF, Shamoon HE, Hart CA (2008) Molecular epidemiology and disease severity of respiratory syncytial virus in relation to other potential pathogens in children hospitalized with acute respiratory infection in Jordan. J Med Virol 80: 168-174.

14. Puzelli S, Valdarchi C, Ciotti M, Dorrucci M, Farchi F, Babakir-Mina M, Perno CF, Donatelli I, Rezza G; Italian ARI Study Group (2009) Viral causes of influenza-like illness: insight from a study during the winters 2004-2007. Med Virol 81: 2066-2071.

\section{Corresponding author}

Dr. Giovanni Rezza

Department of Infectious, Parasitic and Immune-Mediated

Diseases

Istituto Superiore di Sanità

Viale Regina Elena 299

00161 Rome, Italy

Email: giovanni.rezza@iss.it

Conflict of interests: No conflict of interests is declared. 